Check for updates

Cite this: RSC Adv., 2018, 8, 30683

Received 19th July 2018

Accepted 24th August 2018

DOI: $10.1039 / c 8 r a 06135 a$

rsc.li/rsc-advances

\section{Towards cancer diagnostics - an $\alpha$-feto protein electrochemical immunosensor on a manganese(Iv) oxide/gold nanocomposite immobilisation layer}

\begin{abstract}
Azeez O. Idris, ${ }^{a}$ Nonhlangabezo Mabuba ${ }^{\text {ab }}$ and Omotayo A. Arotiba (D) *ab
A novel electrochemical immunosensor for the quantification of $\alpha$-feto protein (AFP) using a nanocomposite of manganese(Iv) oxide nanorods ( $\mathrm{MnO}_{2} \mathrm{NRs}$ ) and gold nanoparticles (AuNPs) as the immobilisation layer is presented. The $\mathrm{MnO}_{2} \mathrm{NRs}$ was synthesised using a hydrothermal method and AuNPs were electrodeposited on a glassy carbon electrode surface. The $\mathrm{MnO}_{2} \mathrm{NRs}$ were characterised with scanning electron microscopy (SEM), high-resolution transmission electron microscopy (HRTEM) and X-ray powder diffraction (XRD). Cyclic voltammetry (CV) and electrochemical impedance spectroscopy (EIS) were used to characterise the immunosensor at each stage of the biosensor preparation. The $\mathrm{MnO}_{2}$ nanorods and AuNPs were applied as the immobilisation layer to efficiently capture the antibodies and amplify the electrochemical signal. Under optimised conditions, the fabricated immunosensor was utilised for the quantification of AFP with a wide dynamic range of 0.005 to $500 \mathrm{ng} \mathrm{mL}^{-1}$ and detection limits of 0.00276 $\mathrm{ng} \mathrm{mL} \mathrm{m}^{-1}$ and $0.00172 \mathrm{ng} \mathrm{mL}^{-1}(\mathrm{~S} / \mathrm{N}=3)$ were obtained from square wave anodic stripping voltammetry and EIS respectively. The nanocomposite modifier enhanced the immunosensor performance. More so, this label-free immunosensor possesses good stability over a period of two weeks when stored at $4{ }^{\circ} \mathrm{C}$ and was selective in the presence of some interfering species.
\end{abstract}

\section{Introduction}

Alpha-feto protein (AFP) is a single-stranded glycoprotein with a molecular weight of $70000 \mathrm{Da}$; it is produced by the yolk sac and fetal liver. ${ }^{1}$ It is an important tumour biomarker often employed for early diagnosis of liver cancer. The concentration of AFP in serum of healthy adults is $25 \mathrm{ng} \mathrm{mL}^{-1}$ but this concentration increases significantly in patients with cancer of the liver. ${ }^{1}$ Thus, the quantification of AFP in human serum plays a significant role in the management of liver carcinoma.

Different analytical techniques such as radioimmunoassay, ${ }^{2}$ enzyme-linked immunosorbent assay, ${ }^{3}$ fluorescence ${ }^{4}$ and chemiluminescence ${ }^{5}$ have been reported for the quantification of AFP. Unfortunately, some of the problems that limit their applications include high turnaround time; high cost, instruments that are not easily operated and requires expertise. On the other hand, electrochemical methods (including electrochemical immunosensors) present themselves as low cost, portable, user-friendly, fast, sensitive, simple and field-borne analytical tool. ${ }^{6}$ These advantages lend electrochemical techniques to environmental analysis, ${ }^{7}$ biotechnology, ${ }^{8}$ pharmaceutical chemistry, ${ }^{9}$ clinical diagnosis ${ }^{10}$ and food industry. ${ }^{11}$

${ }^{a}$ Department of Applied Chemistry, University of Johannesburg, South Africa. E-mail: oarotiba@uj.ac.za

${ }^{b}$ Centre for Nanomaterials Science Research, University of Johannesburg, South Africa
A label-free electrochemical immunosensor involves a direct monitoring of an immunocomplex reaction between antibody and antigen with the advantage of avoiding mediators and tagging. The effective immobilisation of the biomolecules is a crucial step in label-free (and labelled) electrochemical immunosensor. To achieve this, a modifier is carefully selected as a platform or immobilisation layer to assist in capturing the bioreceptor on the electrode and to favour the formation of immunocomplex reaction between the antibody and the antigen. Interestingly, covalent bonding has been reported to be the most explored method in the immobilisation of biomolecules. And glutaraldehyde along with 1-ethyl-3-(3-dimethyl aminopropyl)carbodiimide/ $N$-hydroxysuccinimide (EDC/NHS) is the most prominent cross-linking agents used..$^{12,13}$ The use of cross linkers in immunosensor fabrications increases the step in the biosensor preparation and creates the possibility of introducing bonds that may hinder the bio-recognition process and thus a deviation from biomimicry. ${ }^{14}$ It is therefore necessary to utilise materials that are biocompatible (that will not hinder the biological integrity of the biomolecules) and which can increase the electrode surface area and enhance conductivity. In this light, a composite of gold nanoparticles (AuNPs) and manganese(rv) oxide nanorods $\left(\mathrm{MnO}_{2} \mathrm{NRs}\right)$ was utilised for the first time as a platform for the reported immunosensor.

Gold nanoparticles (AuNPs) have been used in different analytical fields because of their nanoscale size, large surface area, high electron density, rich surface chemistry and 


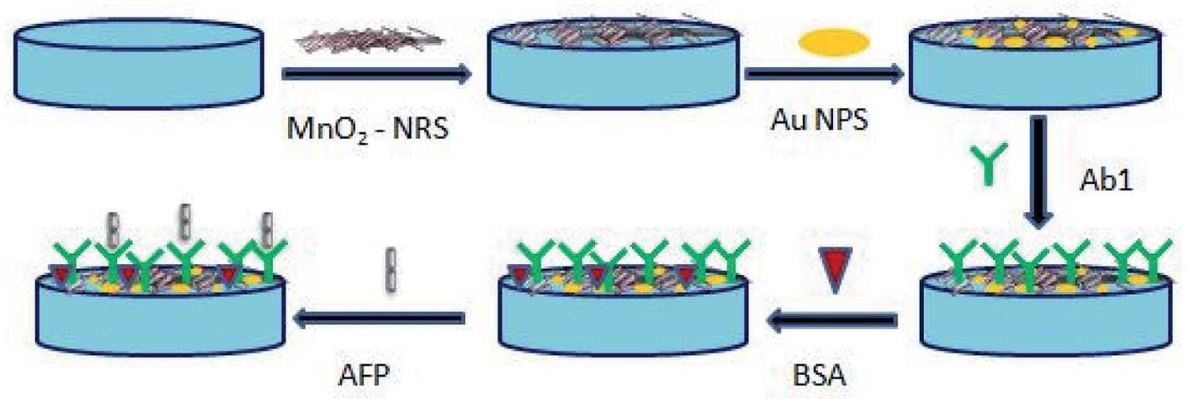

Scheme 1 The scheme for the fabrication of the immunosensor.

biocompatibility properties. ${ }^{15}$ These properties have rendered gold nanoparticles a material of choice in biosensors, ${ }^{16,17}$ chemosensor, ${ }^{18}$ drug,${ }^{19}$ gene delivery, ${ }^{20}$ imaging diagnostics, ${ }^{21}$ photothermal therapy, ${ }^{22}$ photodynamic therapy ${ }^{23}$ and organic/ inorganic electrochemical sensors. ${ }^{23-25}$ Liang et al. reported a highly sensitive signal-simplified AuNPs based electrochemical immunosensor for dibutyl phthalate quantification. ${ }^{26}$ In another report, gold nanoparticles and graphene chitosan nanocomposite were employed for the construction of a labelfree electrochemical immunosensor for carcinoembryonic antigen. ${ }^{27}$ Similarly, a Prussian blue-chitosan-gold nanocomposite film was explored for the fabrication of an amperometric immunosensor for histamine detection. ${ }^{17}$

Manganese(Iv) oxide nanorods $\left(\mathrm{MnO}_{2} \mathrm{NRs}\right)$, though less utilised compared to AuNPs, possess interesting properties such as catalysis, low cost, high surface area, environment-friendliness and excellent electrochemical properties. ${ }^{28}$ Thus, $\mathrm{MnO}_{2} \mathrm{NRs}$ have been explored in batteries, ${ }^{29}$ supercapacitors, ${ }^{30}$ electrocatalysis $^{31}$ and sensor. ${ }^{32}$ Different methods such as thermal, ${ }^{33}$ hydrothermal, ${ }^{34}$ sol-gel method, ${ }^{35}$ sonochemistry ${ }^{36}$ and electrochemical deposition ${ }^{37}$ have been reported for the preparation of $\mathrm{MnO}_{2}$. The advantage of hydrothermal synthetic routes over others is the ability to produce a variety of nanostructured materials, which ranges from nanoparticles to nanorods and nanotubes. The shapes and sizes can be easily controlled by optimising the reaction temperature and time. The reported $\mathrm{MnO}_{2} \mathrm{NRs}$ was synthesised via the hydrothermal route.

Reports on the electrochemical applications of $\mathrm{MnO}_{2} \mathrm{NRs}$ especially in biosensors are scanty. Wang et al. reported a nonenzymatic biosensor for L-cysteine using copper nanoparticles and manganese dioxide-multiwalled carbon nanotubes. ${ }^{38}$ Other reports include the use of $\mathrm{MnO}_{2}$ in the sensing of hydrogen peroxide in living cells ${ }^{39}$ and choline with choline oxidase as bioreceptor. ${ }^{40}$ These recent reports suggest that this material has a potential for biosensor development.

Thus, $\mathrm{MnO}_{2}$ was employed in this work, owing to its nanosize (for increase surface area), conductivity (enhancing of electron/ charge flow) and affinity for the thiol residue in the antibody. ${ }^{38}$ AuNP was used to sandwich the $\mathrm{MnO}_{2}$ further onto the electrode by electrodeposition thus preventing leaching of the $\mathrm{MnO}_{2}$. The sandwich creates a possible metal-metal interaction between the $\mathrm{MnO}_{2}$ and AuNP forming a continuous nano-network that facilitated enhanced electron transfer. In a similar manner to $\mathrm{MnO}_{2}$,
AuNPs has affinity for sulphur residue in the amino acid sulphur atoms in the AFP antibody and this improved the immobilisation capacity of the modified electrode. ${ }^{15}$

\section{Experimental}

\subsection{Materials and instruments}

Alpha-feto protein and anti-AFP (monoclonal) were bought from Celtic Diagnostic (South Africa). Ascorbic acid, urea, bovine serum albumin (BSA), prostate-specific antigen (PSA), human immunoglobulin, carcinoembryonic antigen (CEA), $\mathrm{Na}_{2} \mathrm{HPO}_{4}$, $\mathrm{K}_{3} \mathrm{Fe}(\mathrm{CN})_{6}, \mathrm{NaH}_{2} \mathrm{PO}_{4}, \mathrm{HAuCl}_{4}, \mathrm{KMnO}_{4}$ and $\mathrm{KCl}$ were bought from Sigma Aldrich (South Africa). All chemicals were used as received and all solutions were prepared with ultra-pure water.

The following techniques/instruments were used for characterisation: X-ray diffractometry on a Rigaku Smartlab X-ray diffractometer (USA). Electron micrographs were taken with a scanning electron microscope (TESCAN, Vega 3 XMU, Czech Republic), transmission electron microscopy (JEOL 2100 HRTEM 200 V, Japan). Ivium Compactstat potentiostat (Netherlands) was used for all the electrochemical experiments in a three-electrode system cell comprising glassy carbon as a working electrode, $\mathrm{Ag} /$ $\mathrm{AgCl}(3 \mathrm{M} \mathrm{KCl})$ as a reference electrode and platinum wire as a counter electrode. Cyclic voltammetry (CV) measurements were carried out at a scan rate of $50 \mathrm{mV} \mathrm{s}^{-1}$ and a potential range of $-0.3 \mathrm{~V}$ to $1.0 \mathrm{~V}$. The parameters used for the electrochemical impedance spectroscopy measurements are frequency range of $100 \mathrm{kHz}$ to $100 \mathrm{mHz}$ and a bias potential of $0.22 \mathrm{~V}$.

\subsection{Synthesis of manganese(Iv) nanorods $\left(\mathrm{MnO}_{2} \mathrm{NRs}\right)$}

The $\mathrm{MnO}_{2} \mathrm{NRs}$ was synthesised using method reported in the literature with slight modifications ${ }^{41}$ Briefly, $1.26 \mathrm{~g}$ of $\mathrm{KMnO}_{4}$ and $0.5 \mathrm{~g}$ of $\mathrm{MnSO}_{4} \cdot \mathrm{H}_{2} \mathrm{O}$ were dissolved in $40 \mathrm{~mL}$ of water. The resulting solution was transferred into a Teflon-lined stainless steel autoclave $(50 \mathrm{~mL})$ and heated at $160{ }^{\circ} \mathrm{C}$ for $12 \mathrm{~h}$. The dark brown precipitate formed was centrifuged, washed with ultrapure water and ethanol three times and finally dried at $80^{\circ} \mathrm{C}$. Eqn (1) represents the reaction involved in the formation of $\mathrm{MnO}_{2} \mathrm{NRs}$.

$$
\begin{aligned}
2 \mathrm{KMnO}_{4(\mathrm{~s})}+3 \mathrm{MnSO}_{4(\mathrm{~s})}+2 \mathrm{H}_{2} \mathrm{O}_{(\mathrm{l})} \rightarrow & 5 \mathrm{MnO}_{2(\mathrm{~s})}+\mathrm{K}_{2} \mathrm{SO}_{4(\mathrm{aq})} \\
& +2 \mathrm{H}_{2} \mathrm{SO}_{4(\mathrm{aq})}
\end{aligned}
$$




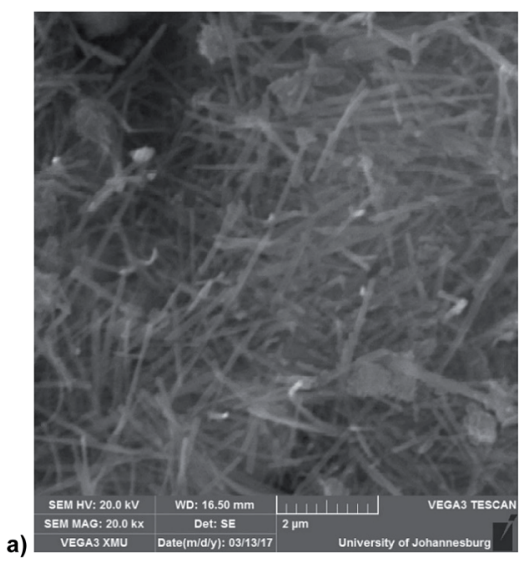

b)
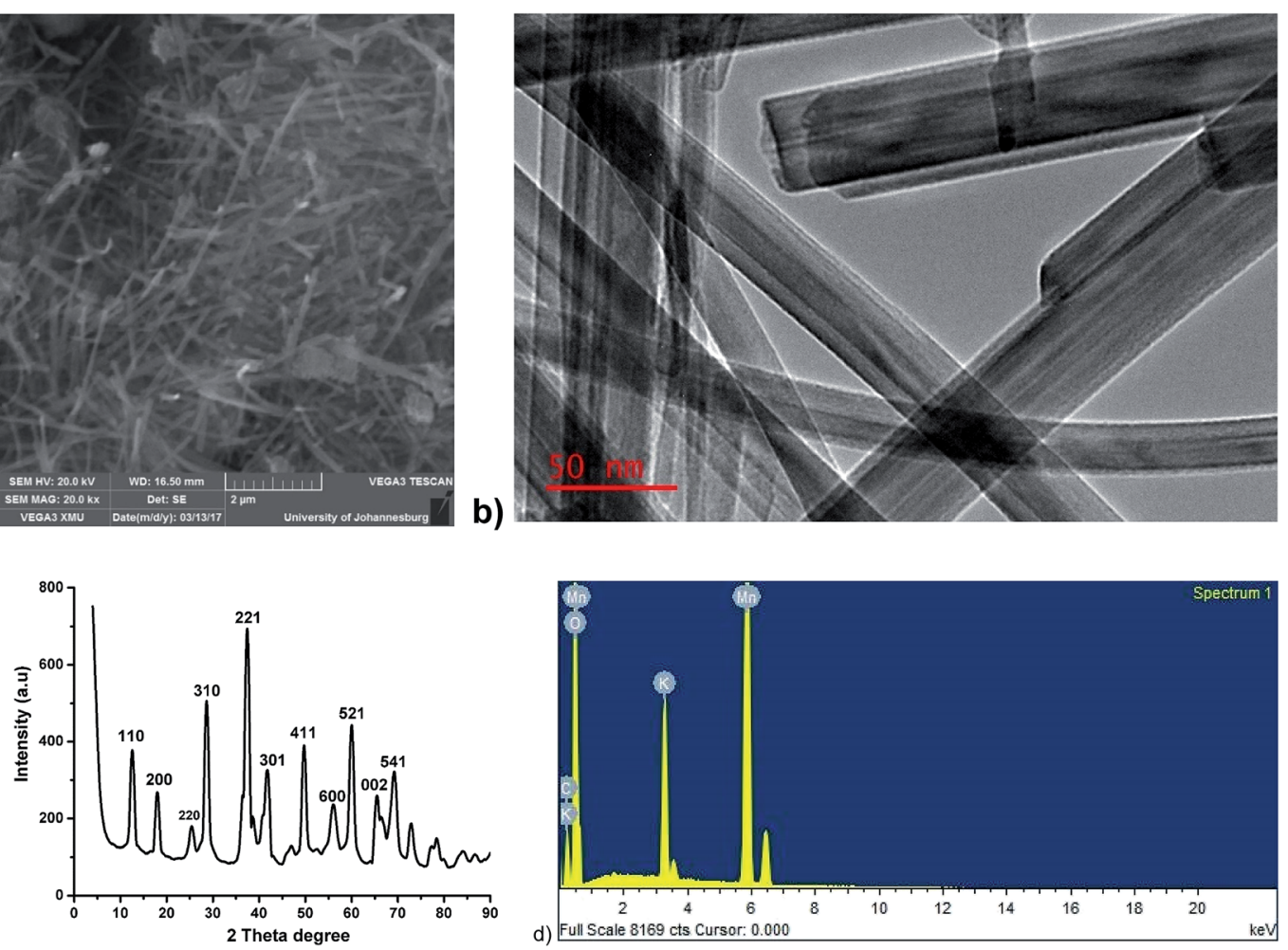
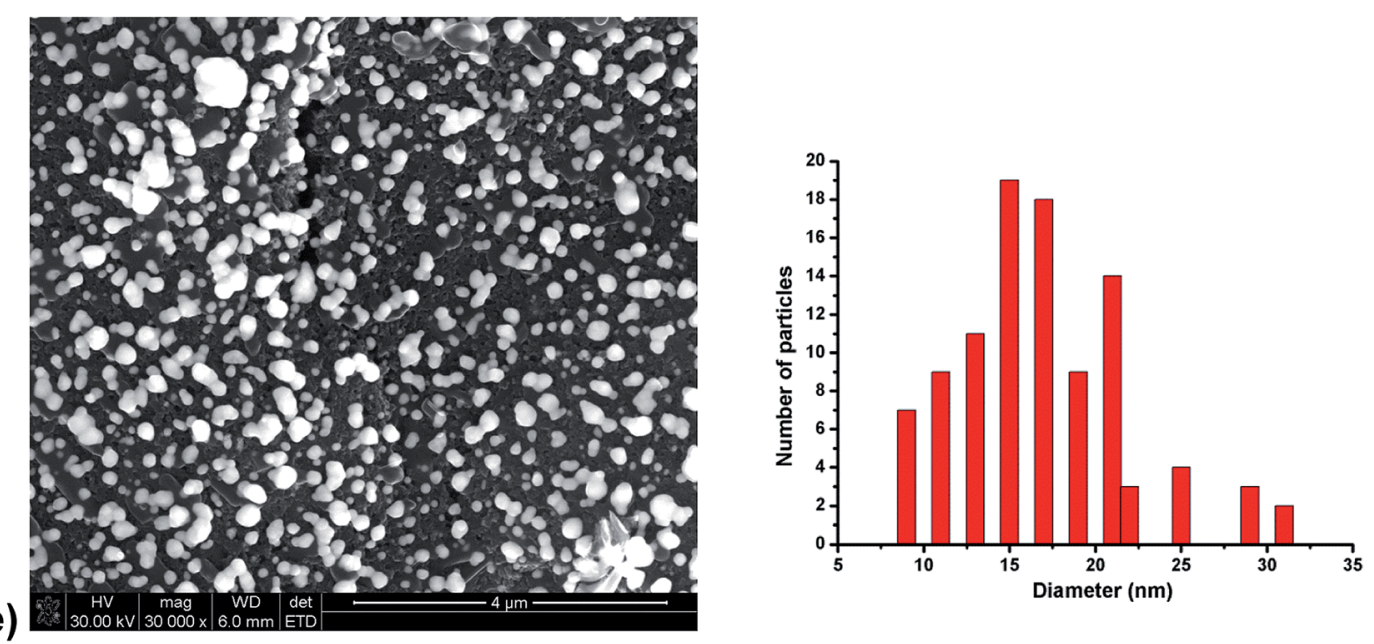

Fig. 1 (a) SEM image of $\mathrm{MnO}_{2} \mathrm{NRs}$ (b) HRTEM image of $\mathrm{MnO}_{2} \mathrm{NRs}$ (c) XRD spectrum of $\mathrm{MnO}_{2} \mathrm{NRs}$ (d) EDX spectrum of $M n \mathrm{O}_{2} \mathrm{NRs}$ (e) SEM image of AuNPs at $4 \mu \mathrm{m}$, particle size distribution of the AuNPs SEM image.

\subsection{Preparation of the immunosensor}

A glassy carbon electrode (GCE) was polished with different diameters of aluminium slurry (1.0, 0.3 and $0.05 \mu \mathrm{m})$ and rinsed ultrasonically in water and ethanol. The cleaned electrode was left to dry at ambient temperature before use. A $30 \mathrm{mg}$ of the synthesised $\mathrm{MnO}_{2}$ was dispersed in $5 \mathrm{~mL}$ of dimethylformamide

Table 1 The results obtained from the circuit fitting for the construction of the immunosensor depicted in Fig. 2B

\begin{tabular}{|c|c|c|c|c|c|c|}
\hline $\begin{array}{l}\text { Circuit } \\
\text { element }\end{array}$ & GCE & $\begin{array}{l}\mathrm{GCE} / \mathrm{MnO}_{2} \\
\mathrm{NRs}\end{array}$ & GCE/AuNPs & $\begin{array}{l}\mathrm{GCE} / \mathrm{MnO}_{2} \\
\text { NRs@AuNPs }\end{array}$ & $\begin{array}{l}\mathrm{GCE} / \mathrm{MnO}_{2} \\
\text { NRs@AuNPs/antibody }\end{array}$ & $\begin{array}{l}\mathrm{GCE} / \mathrm{MnO}_{2} \\
\text { NRs@AuNPs/antibody/BSA }\end{array}$ \\
\hline$R_{\mathrm{S}}(\Omega)$ & 101.40 & 90.65 & 95.63 & 93.18 & 95.55 & 98.87 \\
\hline$R_{\mathrm{ct}}(\Omega)$ & 2225.8 & 65.14 & 34.65 & 20.45 & 87.19 & 94.76 \\
\hline $\mathrm{CPE}(\mathrm{nF})$ & 61.81 & 2.30 & 4.12 & 8.65 & 9.37 & 9.27 \\
\hline
\end{tabular}




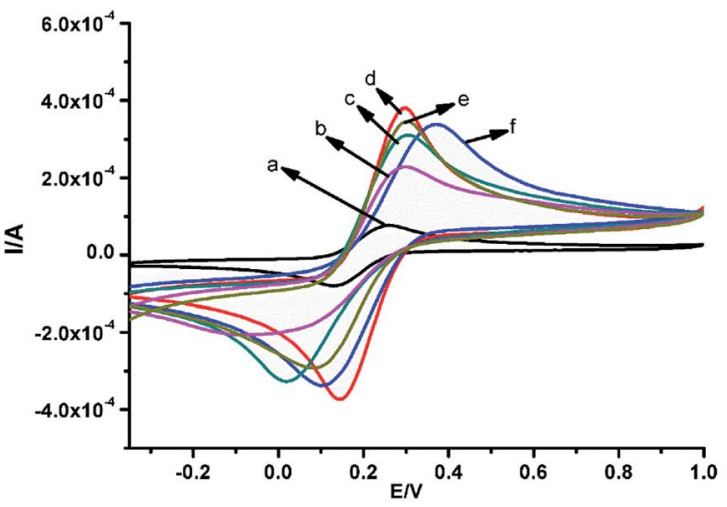

A)

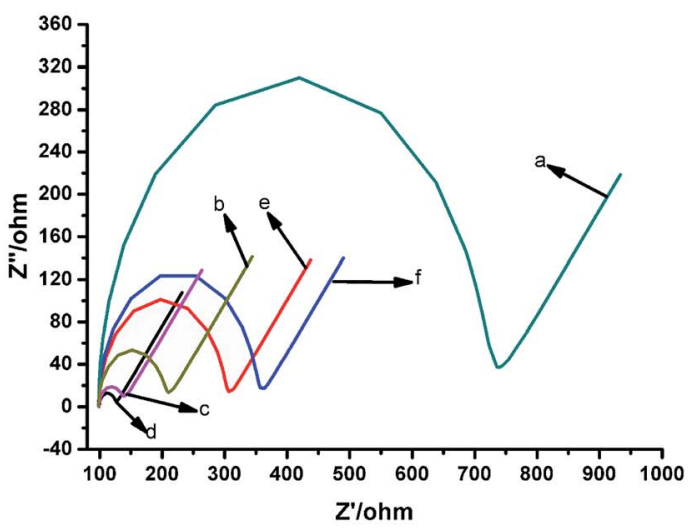

B)

Fig. 2 (A) $\mathrm{CV}$ of $1 \mathrm{mM}\left[\mathrm{Fe}(\mathrm{CN})_{6}\right]^{3-14-}$ in $0.1 \mathrm{M} \mathrm{KCl}$ at $50 \mathrm{mV} \mathrm{s}^{-1}$ scan rate. (B) EIS of $1 \mathrm{mM}\left[\mathrm{Fe}(\mathrm{CN})_{6}\right]^{3-14-}$ in $0.1 \mathrm{M} \mathrm{KCl}$. For both $\mathrm{CV}$ and EIS: where labels (a) bare GCE, (b) GCE/MnO ${ }_{2} N R s$, (c) GCE/AuNPs, (d) GCE/ $\mathrm{MnO}_{2} \mathrm{NRs}\left(\mathrm{AuNPs}\right.$ (e) GCE/MnO${ }_{2} \mathrm{NRs} @ A u N P s / a n t i b o d y, ~(f) ~ G C E /$ $\mathrm{MnO}_{2} \mathrm{NRs}(\mathrm{A} A u N P s / a n t i b o d y+\mathrm{BSA}$.

and sonicated for $1 \mathrm{~h}$. Thereafter, a $20 \mu \mathrm{L}$ of the ultrasonicated solution was dropped on the GCE and allowed to dry overnight at ambient temperature. This electrode was labelled GCE-MnO ${ }_{2}^{-}$ NRs. Gold nanoparticles was electrodeposited onto the GCE$\mathrm{MnO}_{2} \mathrm{NRs}$ from a $10 \mathrm{mM} \mathrm{HAuCl} 4$ solution by cycling a potential from $-400 \mathrm{mV}$ to $1100 \mathrm{mV}$ at a scan rate of $50 \mathrm{mV} \mathrm{s}^{-1}$ for ten cycles. ${ }^{42}$ This electrode was labelled as GCE-MnO ${ }_{2} \mathrm{NRs@AuNPs.}$ The immunosensor was prepared by immersing the GCE-

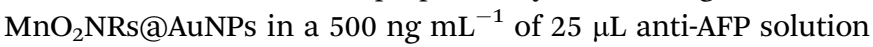
overnight at $4{ }^{\circ} \mathrm{C}$. Finally, the modified electrode was incubated in $0.25 \%$ bovine serum albumin solution for $2 \mathrm{~h}$ to prevent nonspecific binding between antigen and electrode surface.

The step-wise preparation of the immunosensor is presented in scheme 1.

\section{Results and discussion}

The SEM image of $\mathrm{MnO}_{2} \mathrm{NRs}$ shown in Fig. 1a reveals a rodshaped morphology, which was further confirmed by HRTEM image (Fig. 1b). The crystallographic structure of $\mathrm{MnO}_{2} \mathrm{NRs}$ was examined using XRD (Fig. 1c). The extensive diffraction peaks of $\mathrm{MnO}_{2} \mathrm{NRs}$ were observed at $2 \theta=12.8,18.1,26.1,28.8,37.5,41.9$, $49.8,56.3,60.2,65.0$ and $68.2^{\circ}$ which are assigned to (110), (200), (220), (310), (221), (301), (411), (600), (521), (002) and (541) plane diffraction of $\alpha-\mathrm{MnO}_{2}$ with a pure tetragonal phase (JCPDS no. 44-0141). A similar $\mathrm{MnO}_{2}$ XRD pattern has been documented in the literature. ${ }^{43}$ The EDX spectrum in Fig. 1d further confirms the presence of manganese and oxygen in the $\mathrm{MNO}_{2}$ NRs. The morphology and size distribution of AuNPs were characterised as shown in Fig. 1e and $f$, these figures revealed that AuNPs are spherical and well dispersed on the electrode. The size distribution of the AuNPs is small and majority falls within the range from 5 to $31 \mathrm{~nm}$. Based on the statistical analysis of hundred particles, the average diameter of the AuNPs obtained was about $17 \mathrm{~nm}$ (Fig. 1e).

\subsection{Electrochemical characterisation of the immunosensor assembly}

Electrochemical characterisations were carried out with $\mathrm{CV}$ and EIS in $1 \mathrm{mM}\left[\mathrm{Fe}(\mathrm{CN})_{6}\right]^{3-/ 4-}$ in $0.1 \mathrm{M} \mathrm{KCl}$. The bare GCE showed the characteristic ferrocyanide peak (Fig. 2Aa). The peak current signal increased by $75 \%$ on modifying the bare GCE with $\mathrm{MnO}_{2} \mathrm{NRs}$ (Fig. 2Ab). This must have been as a result of the electrocatalytic property of manganese(Iv) oxide nanorods, which helps to facilitate electron transfer at the electrode- a)

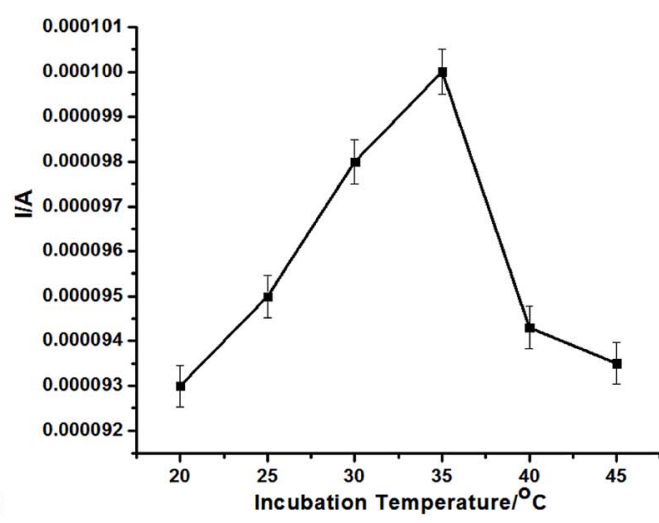

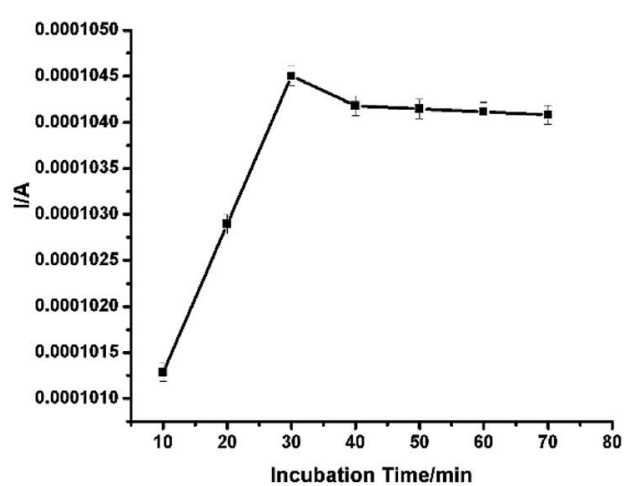

b)

Fig. 3 (a) Incubation temperature from 20 to $45^{\circ} \mathrm{C}$ (b) incubation time from 10 to 70 min in the presence of $50 \mathrm{ng} \mathrm{mL} \mathrm{m}^{-1} \mathrm{AFP}$ using SWV. 


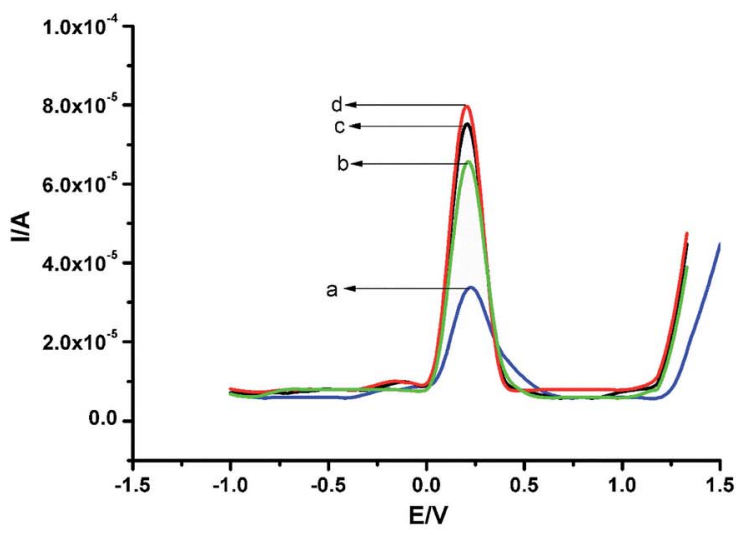

A)

B)

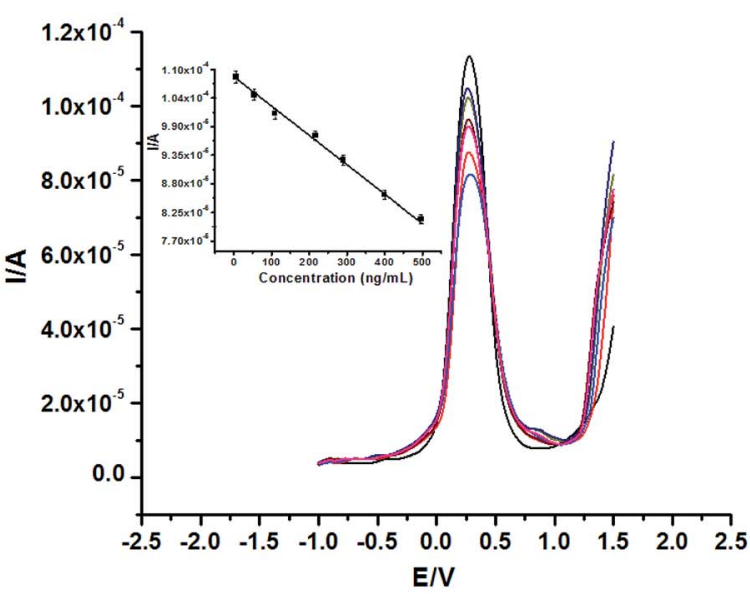

C)

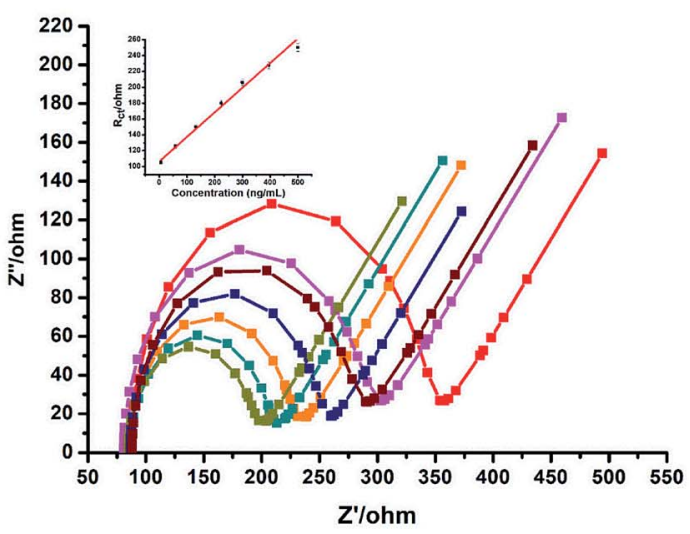

Fig. 4 (A) SWV of different fabricated immunosensors for the detection of $500 \mathrm{ng} \mathrm{mL}^{-1} \mathrm{AFP}$ constructed from (a) GCE/antibody@BSA, (b) GCE/ $\mathrm{MnO}_{2} \mathrm{NRs}$ aantibody/BSA, (c) GCE/AuNPs@antibody/BSA and (d) GCE/ $\mathrm{MnO}_{2} \mathrm{NRs}$ (aAuNPs@antibody/BSA (B) SWV of different concentrations of AFP from 0.005 to $500 \mathrm{ng} \mathrm{mL}^{-1}$ in $1 \mathrm{mM}\left[\mathrm{Fe}(\mathrm{CN})_{6}\right]^{3-/ 4-}$ in $0.1 \mathrm{M} \mathrm{KCl}$ at $25 \mathrm{~Hz}$ (C) EIS of different concentrations of AFP from 0.005 to $500 \mathrm{ng}$ $\mathrm{mL}^{-1}$ using $1 \mathrm{mM}\left[\mathrm{Fe}(\mathrm{CN})_{6}\right]^{3-/ 4-}$ in $0.1 \mathrm{M} \mathrm{KCl}$ and the equivalent circuit employed to fit the experimental impedance data (inset).

solution interface. Similarly, 83\% current enhancement relative to the bare GCE can be observed after modification with AuNPs (Fig. 2Ac). This can be attributed to electroactive surface enhancement, which is a well-reported phenomenon. ${ }^{\mathbf{4 4 , 4 5}}$
Interestingly, a synergic enhancement in peak currents of up to 95\% was obtained after modification with the nanocomposite of $\mathrm{MnO}_{2} \mathrm{NRs@AuNPs} \mathrm{(Fig.} \mathrm{2Ad).} \mathrm{This} \mathrm{resulted} \mathrm{from} \mathrm{the} \mathrm{inter-}$ play of catalysis, conductivity and increase in surface area. Expectedly, there was about a $14 \%$ reduction in peak current signal when $25 \mu \mathrm{L}$ of $500 \mathrm{ng} \mathrm{mL}^{-1}$ anti-AFP solution was immobilised on the surface of the GCE/ $\mathrm{MnO}_{2} \mathrm{NRs@AuNPs}$ as depicted in Fig. 2Ae because of the non-conducting property of anti-AFP, which retarded electron transfer. This electrode was denoted as GCE/MnO${ }_{2}$ NRs@AuNPs/anti-AFP. Finally, the electrode was incubated with $0.25 \%$ bovine serum albumin for approximately $2 \mathrm{~h}$ in order to eliminate non-specific binding between antigen and electrode surface, a slight anodic shift in peak current signal and less than $5 \%$ reduction in peak current signal was observed (Fig. 2Af). This electrode was labelled as $\mathrm{MnO}_{2}$-NRs@AuNPs/anti-AFP/BSA (the immunosensor).

The events that occurred on the electrode surface was interrogated using electrochemical impedance spectroscopy (EIS) and Randle-Sevcik circuit model was used to fit the EIS electrical parameters as shown in Table 1. A similar trend to the voltammetric responses in Fig. 2A was observed when the various electrodes (in Fig. 2A) were interrogated with EIS as depicted in Fig. 2B with the understanding that an increase in current denotes less resistant to flow of current (or lower charge transfer resistance). GCE/ $\mathrm{MnO}_{2}$-NRs and GCE-AuNPs exhibited lower charge transfer resistance $\left(R_{\mathrm{ct}}\right)$ in comparison to the bare electrode (Fig. 2B). This reduction in $R_{\text {ct }}$ agrees with the increase in peak currents signal obtained from the $\mathrm{CV}$ presented in Fig. 2A. The lowest charge transfer of $20.45 \Omega$ was obtained for the nanocomposite as highlighted in (Fig. 2B and Table 1) and this result is in consonance with Fig. 2Ad where the highest currents were observed. As discussed earlier, the synergistic contribution of the nanocomposite increased both the surface area and the rate of electron flow rate thus providing a favourable interface for the redox reaction of the probe. The $R_{\mathrm{ct}}$ increased on modifying with the antibody and BSA owing to the insulating nature of these species. The electrochemical changes in impedance were used as an indicator of successful fabrication of the immunosensor.

\subsection{Optimisation of temperature and incubation time}

The incubation temperature and time were optimised to ascertain the best performing conditions for the immunosensor. The effect of incubation temperature was interrogated from 20 to $45^{\circ} \mathrm{C}$ in the presence of $50 \mathrm{ng} \mathrm{mL}{ }^{-1}$ AFP using square wave voltammetry (Fig. 3a). The highest peak current was observed at $35{ }^{\circ} \mathrm{C}$ and was thus selected as optimum temperature. The decline in current after $35{ }^{\circ} \mathrm{C}$ may be due to the denaturing of the protein (antibody). For optimal immunocomplex formation, the time of incubation was also investigated. As seen in Fig. 3b, the current seems to plateau after $30 \mathrm{~min}$. An optimum incubation time of $30 \mathrm{~min}$ was thus chosen. A similar incubation time has been reported for alphafeto protein immunosensor. ${ }^{5} \mathrm{~A} \mathrm{pH}$ of 7 was used as the optimum $\mathrm{pH}^{46-48}$ 
Table 2 Comparison of the analytical performance of this immunosensor with some related works

\begin{tabular}{lllr}
\hline Immunosensor fabrication & Linear range $\left(\mathrm{ng} \mathrm{mL} L^{-1}\right)$ & Detection limit $\left(\mathrm{ng} \mathrm{mL}^{-1}\right)$ & References \\
\hline CdS nanoparticles/thionine bilayer films & $0.3-250$ & 0.12 & 49 \\
Phenylboronic acid monolayer on gold & $0.1-100$ & 40 & 50 \\
DNA-derived magnetic nanochain probes & $0.01-200$ & 0.04 & 2 \\
Envision complex-antibody co-polymer & $0.005-0.2$ & 0.002 & 51 \\
Pd nanoplates & $0.01-75$ & 0.004 & 52 \\
$\mathrm{MnO}_{2}$ NRs@AuNPs & $0.005-500$ & 0.00276 & Present work
\end{tabular}

\subsection{Detection of AFP by the immunosensor}

Different immunosensors were fabricated on various platforms

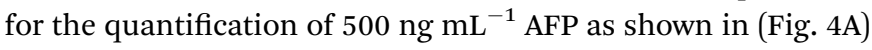
as a proof of concept, the highest peak current signal was obtained from the synergy of $\mathrm{MnO}_{2} @ A u N P s$ in comparison with other platforms. The $\mathrm{MnO}_{2} @$ AuNPs immobilisation platform was thus employed for the fabrication of the immunosensor for the quantification of different concentrations of AFP.

Under the optimised experimental parameters, the fabricated immunosensor was employed to quantify various concentrations of AFP. An inverse proportionality between the current and the AFP concentration was observed with voltammetry (Fig. 4B). This is because the more the AFP bound unto the immunosensor, the more the barrier to the flow of charge due to the insulating property of the AFP or the antigen-antibody complex. On the other hand, EIS measurements show an increase in $R_{\mathrm{ct}}$ with an increase in the concentration of the AFP (Fig. 4C) owing to the same reason of charge transfer hindrance experienced as the immunocomplex is formed. The following were deduced from the biorecognition process: a linear range of 0.005 to $500 \mathrm{ng} \mathrm{mL} \mathrm{m}^{-1}$ with linear regression equation of $Y(\mu \mathrm{A})=$ $108.32-0.0549 x$ (SWV) and $Y=106.352+0.3105 x$ (EIS); a detection limit of $0.00276 \mathrm{ng} \mathrm{mL}^{-1}$ (SWV) and $0.00172 \mathrm{ng}$ $\mathrm{mL}^{-1}$ (EIS) with respective correlation coefficients of 0.9969 and 0.9899. The limit of detection was calculated using, $\frac{3 \times \mathrm{SD}}{S} \mathrm{SD}$ and $S$ represent the standard deviation of the blank and the slope of the calibration graph. The detection limit obtained compares favourably with values reported in the literature (Table 2).

The immunosensor reported in this work has the following advantages (i) it involves a two-step electrode preparation (ii) it has a wider linear range of 0.005 to $500 \mathrm{ng} \mathrm{mL}^{-1}$ (iii) the manganese nanorods used is low cost, relatively abundant, environmentally friendly and excellent electrochemical properties (iv) the quantification of AFP was carried out using SWV and EIS. The lower detection limit obtained must have been because of the synergic combination of the properties of both $\mathrm{MnO}_{2}$-NRs and AuNPs.

\subsection{Stability, reproducibility and selectivity}

To investigate the stability of the fabricated immunosensor, the current response was taken after two weeks of storage at $4{ }^{\circ} \mathrm{C}$. A decrease in current response of $5.2 \%$ was observed (Fig. 5a). This marginal current decrease suggests a good stability. To

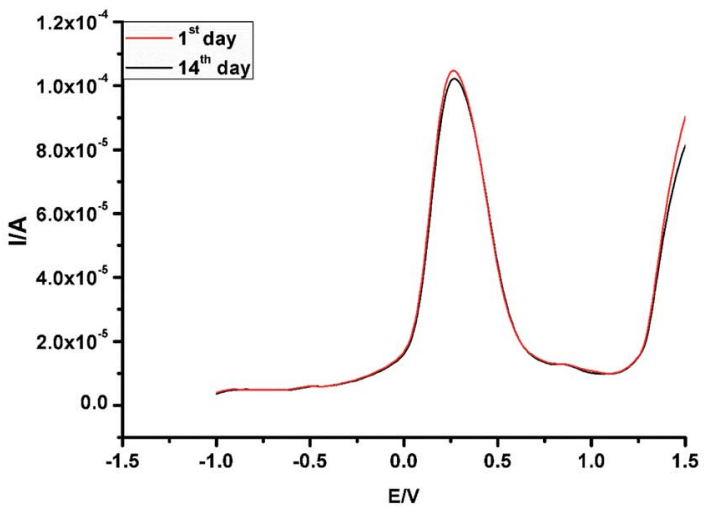

a)

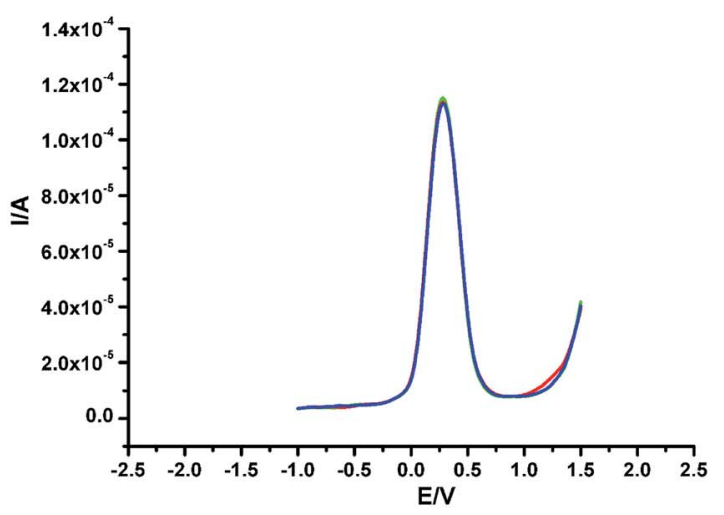

b)

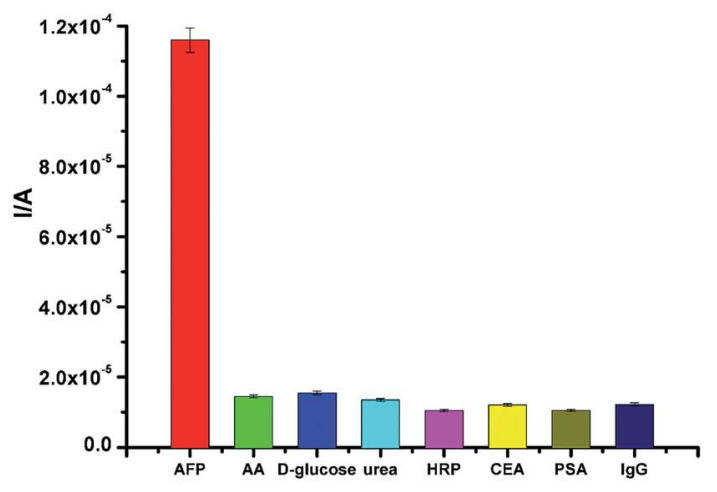

c)

Fig. 5 (a) Stability test: day 1 to day 14 by SWV in $1 \mathrm{mM}\left[\mathrm{Fe}(\mathrm{CN})_{6}\right]^{3-/ 4-}$ at $25 \mathrm{~Hz}$ (b) SWV of different immunosensors for reproducibility (c) selectivity result of the fabricated immunosensor in presence of interferences. 
Table 3 Quantification of AFP in serum samples

\begin{tabular}{|c|c|c|c|c|}
\hline $\begin{array}{l}\text { Serum sample } \\
\left(\mathrm{ng} \mathrm{mL} \mathrm{mL}^{-1}\right)\end{array}$ & $\begin{array}{l}\text { The addition } \\
\text { content }\left(\mathrm{ng} \mathrm{mL}^{-1}\right)\end{array}$ & The detection content $\left(\mathrm{ng} \mathrm{mL}^{-1}\right)$ & $\operatorname{RSD}(\%, n=6)$ & Recovery (\%) \\
\hline \multirow[t]{2}{*}{0.00} & 10.0 & $10.02,9.99,10.00,9.97,10.01$ & 0.0192 & 99.98 \\
\hline & 300.0 & $299.92,300.05,299.97,300.12,300.08$ & 0.0847 & 100.01 \\
\hline
\end{tabular}

ascertain reproducibility of the proposed immunosensor, the current response was interrogated by the analysis of the same concentration of AFP (50 $\mathrm{ng} \mathrm{mL}^{-1}$ ) using four different GCE prepared under the same experimental conditions as depicted in (Fig. 5b). A relative standard deviation (RSD) of $c a .5 .3 \%$ was calculated for the different measurements taken.

In order to investigate the selectivity of the sensor, it was incubated with $100 \mathrm{ng} \mathrm{mL}{ }^{-1}$ in the presence of the same concentration of interfering species (including ascorbic acid, prostate-specific antigen (PSA), D-glucose, carcinoembryonic antigen (CEA), urea, horseradish peroxidase (HRP) and human immunoglobulin (IgG)) (Fig. 5c.). The current response due to the interfering substances was $5.8 \%$ less than the current change measured in the absence of interfering substances. In summary, the fabricated immunosensor displayed good reproducibility, stability and selectivity.

\subsection{Application of the immunosensor}

The application of the proposed immunosensor for the detection of AFP was examined by standard addition method using a human serum, which was diluted 100 times with PBS solution. The concentrations of AFP added to the diluted human serum samples were $\left(10.0,100.0\right.$ and $\left.300.0 \mathrm{ng} \mathrm{mL}^{-1}\right)$. Each of this sample was analysed five times. The recovery was in the range of 99.98-100.03\% and relative standard deviation of $0.0192-$ $0.0847 \%$ (Table 3). This showed that the proposed immunosensor has a potential towards real quantification of AFP in a serum sample.

\section{Conclusion}

A novel nanocomposite of $\mathrm{MnO}_{2} \mathrm{NRs}$ and AuNPs was used as electrode material for the fabrication of an electrochemical immunosensor for a cancer biomarker AFP. A synergy between the nanocomposite yielded an AFP immunosensor with good detection limit, reproducibility and selectivity suggesting the favourable potential of this material combination. This work also laid a foundation for further exploration of the scarcely reported $\mathrm{MnO}_{2} \mathrm{NRs}$ in biosensors development. The detection limits obtained from both voltammetry and impedance are in agreement, lending the biosensor to dual transduction signals. The possibility of a real application was carried out by detection of AFP in human serum. This fabricated immunosensor holds good promises for electrochemical immunosensor for different cancer biomarkers.

\section{Conflicts of interest}

There are no conflicts of interest to declare.

\section{Acknowledgements}

This work was supported by the National Research Foundation of South Africa (Thuthuka Grant No. 107066 and CPRR Grant number: 98887); the Centre for Nanomaterials Science Research, University of Johannesburg (UJ) South Africa and the Faculty of Science, UJ South Africa.

\section{References}

1 Y. Chen, Y. Zhao, L. Feng, J. Zhang, J. Zhang and G. Feng, Association between alpha-fetoprotein and metabolic syndrome in a Chinese asymptomatic population: a crosssectional study, Lipids Health Dis., 2016, 15, 1-9.

$2 \mathrm{~N}$. Gan, L. Jia and L. Zheng, A Novel Sandwich Electrochemical Immunosensor Based on the DNA-Derived Magnetic Nanochain Probes for Alpha-Fetoprotein, $J$. Autom. Methods Manage. Chem., 2011, 2011, 1-7.

3 Y. Liu, B. Lin, D. Zeng, Y. Zhu, J. Chen, Q. Zheng, J. Dong and J. Jiang, Alpha-fetoprotein level as a biomarker of liver fibrosis status: a cross-sectional study of 619 consecutive patients with chronic hepatitis B, Gastroenterology, 2014, 14, 1-8.

4 Y. Wang, L. Chen, M. Liang, H. Xu, S. Tang, H. Yang and H. Song, Sensitive fluorescence immunoassay of alphafetoprotein through copper ions modulated growth of quantum dots in situ, Sens. Actuators, B, 2017, 247, 408-413.

5 Z. Huang, W. Han, Y. Wu, X. Hu, Y. Yuan and W. Chen, Magnetic electrochemiluminescent immunoassay with quantum dots label for highly efficient detection of the tumor marker $\alpha$-fetoprotein, J. Electroanal. Chem., 2017, 785, 8-13.

6 A. Kim, T. Jung, M. S. Kim, I. Kim, K. Kim, K. Hoe and S. Ko, Functional fusion proteins and prevention of electrode fouling for a sensitive electrochemical immunosensor, Anal. Chim. Acta, 2017, 967, 70-77.

7 N. Van Chuc, N. H. Binh, C. T. Thanh and N. Van Tu, Electrochemical Immunosensor for Detection of Atrazine Based on Polyaniline/Graphene, J. Mater. Sci. Technol., 2016, 32, 539-544.

8 J. Bhardwaj, S. Devarakonda, S. Kumar and J. Jang, Development of a paper-based electrochemical immunosensor using an antibody-single walled carbon 
nanotubes bio-conjugate modified electrode for label-free detection of foodborne pathogens, Sens. Actuators, B, 2017, 253, 115-123.

9 S. Shi, S. Reisberg, G. Anquetin, V. Noël, M. C. Pham and B. Piro, General approach for electrochemical detection of persistent pharmaceutical micropollutants: application to acetaminophen, Biosens. Bioelectron., 2015, 72, 205-210.

10 R. Akter, B. Jeong, Y. Lee, J. Choi and A. Rahman, Femtomolar detection of cardiac troponin I using a novel label-free and reagent-free dendrimer enhanced impedimetric immunosensor, Biosens. Bioelectron., 2017, 91, 637-643.

11 R. C. Alves, F. B. Pimentel, H. P. A. Nouws, R. C. B. Marques, M. B. González-garcía, M. B. Oliveira and C. Delerue-matos, Detection of Arah 1 (a major peanut allergen) in food using an electrochemical gold nanoparticle-coated screen-printed immunosensor, Biosens. Bioelectron., 2015, 64, 19-24.

12 R. Akter, B. Jeong, Y. Lee, J. Choi and A. Rahman, Femtomolar detection of cardiac troponin I using a novel label-free and reagent-free dendrimer enhanced impedimetric immunosensor, Biosens. Bioelectron., 2017, 91, 637-643.

13 R. Raghav and S. Srivastava, Immobilization strategy for enhancing sensitivity of immunosensors: L-asparagine AuNPs as a promising alternative of EDC - NHS activated citrate - AuNPs for antibody immobilization, Biosens. Bioelectron., 2016, 78, 396-403.

14 N. Soda and O. A. Arotiba, A polyamidoamine dendrimerstreptavidin supramolecular architecture for biosensor development, Bioelectrochemistry, 2017, 118, 14-18.

15 M. Hadi, H. Amani, A. Akbar, H. Pazoki-toroudi and B. Sedighimoghaddam, Research various methods of gold nanoparticles (GNPs) conjugation to antibodies, Sens. Biosensing Res., 2016, 9, 17-22.

16 A. Neshastehriz, M. Tabei, S. Maleki, S. Eynali and A. Shakeri-zadeh, Photothermal therapy using folate conjugated gold nanoparticles enhances the effects of 6 MV X-ray on mouth epidermal carcinoma cells, $J$. Photochem. Photobiol., B, 2017, 172, 52-60.

17 X. Dong, J. Yang, L. Luo, Y. Zhang, C. Mao and Y. Sun, Portable amperometric immunosensor for histamine detection using Prussian blue-chitosan-gold nanoparticle nanocomposite films, Biosens. Bioelectron., 2017, 98, 305309.

18 P. Srisuratsiri, P. Kanjanasirirat, A. Chairongdua and $\mathrm{P}$. Kongsaeree, Reversible rhodamine-alkyne $\mathrm{Au}^{3+}$-selective chemosensor and its bioimaging application, Tetrahedron Lett., 2017, 58, 3194-3199.

19 T. Shaikh, A. Pandey, F. N. Talpur, A. Kaushik and J. H. Niazi, Gold nanoparticles based sensor for in vitro analysis of drugdrug interactions using imipramine and isoniazid drugs: a proof of concept approach, Sens. Actuators, B, 2017, 252, 1055-1062.

20 P. Zhang, B. Li, J. Du and Y. Wang, Regulation the morphology of cationized gold nanoparticles for effective gene delivery, Colloids Surf., B, 2017, 157, 18-25.
21 P. Manivasagan, S. Bharathiraja, N. Quang, B. Jang, Y. Oh, I. Gweon and J. Oh, Doxorubicin-loaded fucoidan capped gold nanoparticles for drug delivery and photoacoustic imaging, Int. J. Biol. Macromol., 2016, 91, 578-588.

22 R. Cheheltani, R. M. Ezzibdeh, P. Chhour, K. Pulaparthi, J. Kim, M. Jurcova, J. C. Hsu, C. Blundell, H. I. Litt, V. A. Ferrari, H. R. Allcock, C. M. Sehgal and D. P. Cormode, Tunable biodegradable gold nanoparticles as contrast agents for computed tomography and photoacoustic imaging, Biomaterials, 2016, 102, 87-97.

23 M. E. Alea-reyes, J. Soriano, I. Mora-espí, M. Rodrigues, D. A. Russell, L. Barrios and L. Pérez-garcía, Amphiphilic gemini pyridinium-mediated incorporation of $\mathrm{Zn}$ (II) mesotetrakis (4-carboxyphenyl) porphyrin into water-soluble gold nanoparticles for photodynamic therapy, Colloids Surf., B, 2017, 158, 602-609.

24 A. Shah, M. Akhtar, S. Aftab and A. Hassan, Gold copper alloy nanoparticles (Au-CuNPs) modified electrode as an enhanced electrochemical sensing platform for the detection of persistent toxic organic pollutants, Electrochim. Acta, 2017, 241, 281-290.

25 A. O. Idris, J. P. Mafa, N. Mabuba and O. A. Arotiba, Nanogold Modified Glassy Carbon Electrode for the Electrochemical Detection of Arsenic in Water, Russ. J. Electrochem., 2017, 53, 190-197.

26 Y. Liang, Z. Zhang, Z. Liu, K. Wang, X. Wu and K. Zeng, A highly sensitive signal-amplified gold nanoparticle-based electrochemical immunosensor for dibutyl phthalate detection, Biosens. Bioelectron., 2017, 91, 199-202.

27 S. Samanman, A. Numnuam, W. Limbut, P. Kanatharana and P. Thavarungkul, Highly-sensitive label-free electrochemical carcinoembryonic antigen immunosensor based on a novel $\mathrm{Au}$ nanoparticles-graphene-chitosan nanocomposite cryogel electrode, Anal. Chim. Acta, 2015, 853, 521-532.

28 L. Feng, G. Li, S. Zhang and Y. Xin, Decoration of carbon cloth by manganese oxides for flexible asymmetric supercapacitors, Ceram. Int., 2017, 43, 8321-8328.

29 Z. Khan, A. Zahoor, N. A. M. Barakat and H. Yong, The $(2 \times$ 2) tunnels structured manganese dioxide nanorods with a phase for lithium air batteries, Superlattices Microstruct., 2016, 90, 184-190.

30 M. Yu, T. Zhai, X. Lu, X. Chen, S. Xie, W. Li, C. Liang, W. Zhao, L. Zhang and Y. Tong, Manganese dioxide nanorod arrays on carbon fabric for flexible solid-state supercapacitors, J. Power Sources, 2013, 239, 64-71.

31 M. S. El-deab, Electrocatalysis by nanoparticles: oxidation of formic acid at manganese oxide nanorods-modified $\mathrm{Pt}$ planar and nanohole-arrays, J. Adv. Res., 2010, 1, 87-93.

32 S. H. Lee, J. Yang, Y. J. Han, M. Cho and Y. Lee, Rapid and highly sensitive MnOx nanorods array platform for a glucose analysis, Sens. Actuators, B, 2015, 218, 137-144.

33 Z. Yang, Y. Zhang, W. Zhang, X. Wang, Y. Qian, X. Wen and S. Yang, Nanorods of manganese oxides: Synthesis, characterization and catalytic application, J. Solid State Chem., 2006, 179, 679-684. 
34 L. Lan, Q. Li, G. Gu, H. Zhang and B. Liu, Hydrothermal synthesis of c-MnOOH nanorods and their conversion, $J$. Alloys Compd., 2015, 644, 430-437.

35 S. Ching, E. J. Welch, S. M. Hughes, A. B. F. Bahadoor and S. L. Suib, Nonaqueous Sol-Gel Syntheses of Microporous Manganese Oxides, Chem. Mater., 2002, 14, 1292-1299.

36 A. Zolfaghari, F. Ataherian, M. Ghaemi and A. Gholami, Capacitive behavior of nanostructured $\mathrm{MnO}_{2}$ prepared by sonochemistry method, Electrochim. Acta, 2007, 52, 28062814.

37 M. Kundu and L. Liu, Direct growth of mesoporous $\mathrm{MnO}_{2}$ nanosheet arrays on nickel foam current collectors for high-performance pseudocapacitors, J. Power Sources, 2013, 243, 676-681.

38 X. Wang, C. Luo, L. Li and H. Duan, Highly selective and sensitive electrochemical sensor for L-cysteine detection based on graphene oxide/multiwalled carbon nanotube/ manganese dioxide/gold nanoparticles composite, $J$. Electroanal. Chem., 2015, 757, 100-106.

39 W. Bai, X. Zhang, S. Zhang, Q. Sheng and J. Zheng, Acidification of manganese dioxide for ultrasensitive electrochemical sensing of hydrogen peroxide in living cells, Sens. Actuators, B, 2017, 242, 718-727.

40 G. Yu, Q. Zhao, W. Wu, X. Wei and Q. Lu, A facile and practical biosensor for choline based on manganese dioxide nanoparticles synthesized in situ at the surface of electrode by one-step electrodeposition, Talanta, 2016, 146, 707-713.

41 J. Zhang, J. Guo, H. Xu and B. Cao, Reactive-Template Fabrication of Porous $\mathrm{SnO}_{2}$ Nanotubes and Their Remarkable Gas-Sensing Performance, ACS Appl. Mater. Interfaces, 2013, 5, 7893-7898.

42 A. O. Idris, J. P. Mafa, N. Mabuba and O. A. Arotiba, Dealing with interference challenge in the electrochemical detection of $\mathrm{As}(\mathrm{III})-\mathrm{a}$ complexometric masking approach, Electrochem. Commun., 2016, 64, 18-20.

43 Y. Miao, L. Ren, L. Shi and W. Li, Hydrothermal synthesis of manganese oxide nanorods as a highly active support for gold nanoparticles in CO oxidation and their stability at low temperature, $R S C A d v$., 2015, 5, 62732-62738.
44 J. F. Huang and H. H. Chen, Gold-nanoparticle-embedded nafion composite modified on glassy carbon electrode for highly selective detection of arsenic(III), Talanta, 2013, 116, 852-859.

45 A. O. Idris, N. Mabuba and O. A. Arotiba, Electrochemical codetection of Arsenic and Selenium on a Glassy Carbon Electrode Modified with Gold Nanoparticles, Int. J. Electrochem. Sci., 2017, 12, 10-21.

46 C. Zhou, D. Liu, L. Xu, Q. Li, J. Song, S. Xu, R. Xing and H. Song, A sensitive label-free amperometric immunosensor for alpha-fetoprotein based on gold nanorods with different aspect ratio, Sci. Rep., 2015, 5, 1-7.

47 N. Li, H. Ma, W. Cao, D. Wu, T. Yan, B. Du and Q. Wei, Highly sensitive electrochemical immunosensor for the detection of alpha fetoprotein based on PdNi nanoparticles and N-doped graphene nanoribbons, Biosens. Bioelectron., 2015, 74, 786-791.

48 Y. Dai, Y. Cai, Y. Zhao, D. Wu, B. Liu, R. Li, M. Yang, Q. Wei, B. Du and H. Li, Sensitive sandwich electrochemical immunosensor for alpha fetoprotein based on prussian blue modified hydroxyapatite, Biosens. Bioelectron., 2011, 28, 112-116.

49 X. Miao, R. Yuan, Y. Chai, Y. Shi and Y. Yuan, Electrochemical immunoassay for alpha-1-fetoprotein based on CdS nanoparticles and thionine bilayer films modified glass carbon electrode, Biochem. Eng. J., 2008, 38, 9-15.

50 Z. Wang, Y. Tu and S. Liu, Electrochemical immunoassay for alpha-fetoprotein through a phenylboronic acid monolayer on gold, Talanta, 2008, 77, 815-821.

51 P. Xiong, N. Gan, Y. Cao, F. Hu, T. Li and L. Zheng, An ultrasensitive electrochemical immunosensor for alphafetoprotein using an envision complex-antibody copolymer as a sensitive label, Materials, 2012, 5, 2757-2772.

52 H. Wang, H. Li, Y. Zhang, Q. Wei, H. Ma, D. Wu, Y. Li, Y. Zhang and B. Du, Label-free immunosensor based on Pd nanoplates for amperometric immunoassay of alphafetoprotein, Biosens. Bioelectron., 2014, 53, 305-309. 